\title{
Propionibacterium acnes causing an aortic root abscess
}

\author{
S M Horner, M F Sturridge, R H Swanton
}

\begin{abstract}
A case of endocarditis caused by Propionibacterium acnes associated with an aortic root abscess is presented. This supports the current opinion that aortic root abscesses are not necessarily associated with microorganisms of high virulence.
\end{abstract}

\section{(Br Heart J 1992;68:218-20)}

Endocarditis caused by Propionibacterium is very rare despite the frequent presence of the bacterium in sebaceous glands and in the bypass filter during operation. ${ }^{1} \mathrm{~A}$ case is presented in which endocarditis of a prosthetic aortic valve caused by Propionibacterium was associated with an aortic root abscess.

\section{Case report}

A 34 year old man was admitted after a cerebrovascular accident. At the age of 13 he had had rheumatic fever. In 1978 he had been admitted with pericarditis and at that time an aortic regurgitant murmur was heard. He had subsequently progressed well until 1986 when he noticed that he was short of breath on exertion and more tired than usual. On examination he had the signs of aortic regurgitation. Cardiac catheterisation showed severe aortic regurgitation, a normal aortic root, and a dilated ventricle with good function. $\mathrm{He}$ underwent aortic valve replacement with a Starr-Edwards prosthesis as the native valve showed the signs of rheumatic damage. He made a good recovery.

On 19 July 1989 he was admitted to hospital with numbness and weakness in his right arm and leg which had come on suddenly. He was smoking 10 cigarettes a day and taking warfarin. On examination he looked well and was apyrexial. Auscultation of his heart showed only the signs of a normally functioning aortic valve prosthesis. He had mild expressive dysphasia and decreased sensation over the right side of his face, right arm, and right leg. Muscle power in all muscle groups of the right arm and leg was decreased, and the tendon reflexes were all brisk, and the right plantar response was upgoing. His international normalised ratio was $2 \cdot 4$ haemoglobin $14 \cdot 1 \mathrm{~g} / 1$, white cell count $15 \cdot 7 \times$ $10^{9} / 1$, and erythrocyte sedimentation rate $27 \mathrm{~mm} / \mathrm{h}$. A computerised tomographic scan of his brain showed a haemorrhage in the left occipital region surrounded by oedema (fig 1).

Blood cultures were incubated for three weeks without terminal subculture. Two sets of blood cultures produced a growth of Propionibacterium acnes in the anaerobic bottles after six days of incubation. Another two sets yielded a similar organism after two weeks of incubation. A midstream urine culture was negative. The chest $x$ ray film and an abdominal ultrasound showed no abnormalities. No complement fixing antibodies were detected for Coxiella species or Chlamydia psittaci. An autoantibody screen was negative.

The Propionibacterium acnes isolated was sensitive to penicillin, gentamicin, vancomycin, teicoplanin, and rifampicin. The minimum inhibitory concentrations were $0.03 \mathrm{mg} / 1,1 \mathrm{mg} / 1,0.25 \mathrm{mg} / 1,0.06 \mathrm{mg} / \mathrm{l}$, and $0.004 \mathrm{mg} / 1$ respectively. Minimum bactericidal concentrations were $0.12 \mathrm{mg} / \mathrm{l}, 16 \mathrm{mg} / \mathrm{l}$, $0.5 \mathrm{mg} / 1,0.25 \mathrm{mg} / 1$, and $0.5 \mathrm{mg} / 1$. The patient was treated with benzyl penicillin $(2 \cdot 4 \mathrm{~g}$ every four hours) and gentamicin was added when his fever failed to resolve within five days. The serum bactericidal dilution was $1 / 4$ at peak and $1 / 2$ at trough. His fever did not respond so antibiotic treatment was changed to vancomycin $(1 \mathrm{~g})$ and rifampicin $(300 \mathrm{mg})$ twice daily giving a serum bactericidal dilution of $1 / 16$ at peak and $1 / 8$ at trough. His symptoms still did not improve, suggesting that a root abscess might be present. An early diastolic murmur was heard and echocardiography suggested the presence of an aortic abscess in showing thickening of the anterior wall of the aortic root and aortic regurgitation. Aortography confirmed an aortic root abscess

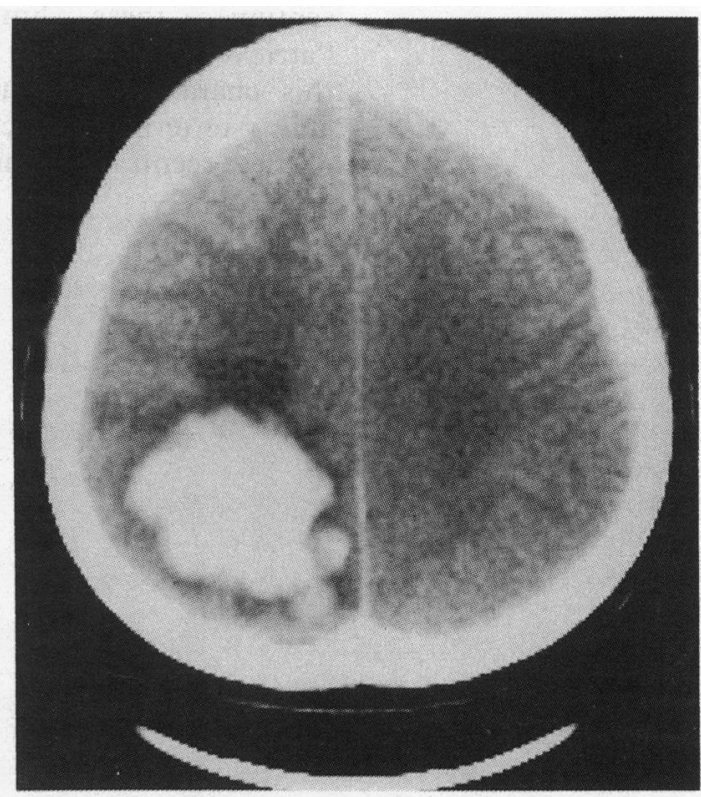

Figure 1 Computerised tomographic head scan showing a large occipital haemorrhage.
Department of Hospital Mortimer S M Horner Surgery, Middlesex Hospital, Mortime Street, London Correspondence to Dr S M Horner, Middlesex Hospital, Mortimer Street, London W1N 8AA. 
Figure 2 Aortogram showing an aortic root abscess.

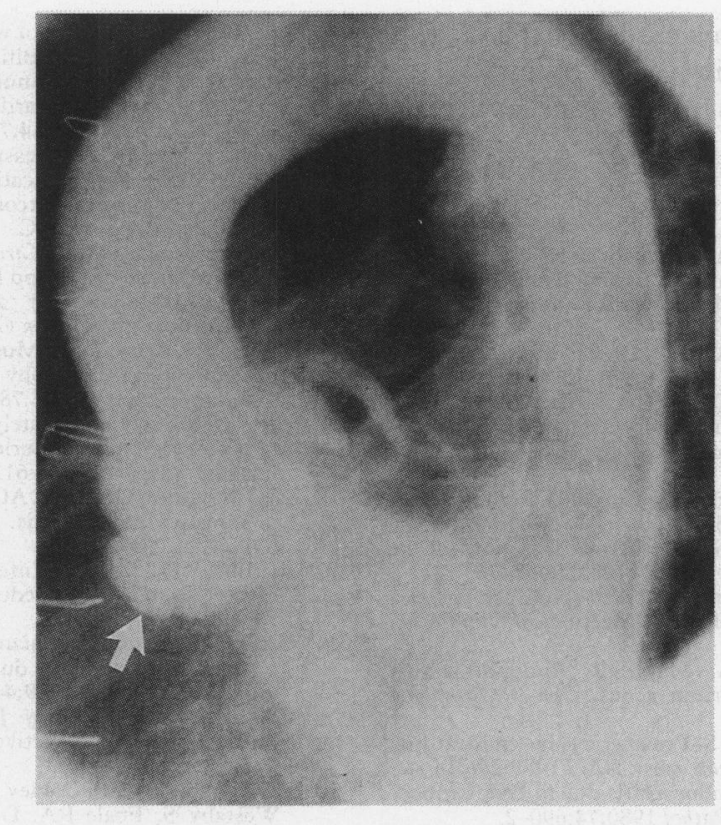

(fig 2). The patient developed the "red man" response to vancomycin and the antibiotics were changed to teicoplanin ( $400 \mathrm{mg}$ ) once daily. But increasing pruritus forced a further change in antibiotic treatment to benzyl penicillin and gentamicin. In view of his recent intracerebral bleed, digital subtraction angiography of his cerebral arteries was undertaken and was normal.

$\mathrm{He}$ underwent replacement of the aortic valve and repair of an aortic root abscess; one suture caused complete heart block and was removed but first degree heart block developed on tightening the other sutures. After the operation he developed left bundle branch block and first degree heart block and thus a permanent pacing system was inserted. This was initially a VVI system but when he became dependent on the pacemaker he had symptoms of dyspnoea and tiredness so the pacemaker was replaced by a dual chamber system. This left him symptom free. He continued to receive benzyl penicillin for six weeks after surgery and he has made a complete recovery.

\section{Discussion}

Propionibacterium acnes is often considered to be a contaminant ${ }^{2}$ but it has been found to be the principal pathogen in meningitis, ${ }^{3}$ scalp pustules, ${ }^{4}$ osteomyelitis, ${ }^{5}$ central nervous system shunt infection, ${ }^{6}$ endophthalmitis ${ }^{7}$ and septic arthritis. ${ }^{2}$ Propionibacterium acnes is also a rare cause of infective endocarditis. ${ }^{8-10}$ It has been suggested that aortic root abscesses are caused by bacteria that are particularly virulent ${ }^{1112}$ although this is not borne out by later studies ${ }^{1314}$ or this case. Propionibacterium acnes is a slow growing anaerobic Gram positive coryneform. It has a pathogenic role in acne vulgaris and is found in sebaceous glands, thus cleaning the skin does not prevent operative contamination. Indeed Propionibacterium species can often be isolated from the blood of patients undergoing cardiopulmonary bypass who are given flucloxacillin and tobramycin prophylaxis (37\%) but rarely from those receiving teicoplanin $(2 \%) .^{1}$ It is thus surprising that infection by Propionibacterium species is so rarely documented and it has been suggested that this is due to the lack of good laboratory anaerobic conditions and prolonged culture. ${ }^{8}$ Propionibacterium acnes is normally sensitive to penicillin, tetracycline, and teicoplanin.

In infective endocarditis, spread of infection to surrounding structures is more common with aortic valves. This may result in an aortic root abscess, annular erosion of the aortic root, mycotic aneurysm, or involvement of the aorticomitral apparatus. Aortic root abscess is more common with prosthetic valve endocarditis occurring in $52 \%$ compared with $15 \%$ of cases of native valve endocarditis. ${ }^{13}$ Cross sectional echocardiography is helpful in identifying aortic root abscesses but few patients $(<5 \%)$ have the obvious finding of an echo free abscess cavity and thus the diagnosis rests on associated findings such as the wall of the aorta being more than $10 \mathrm{~mm}$ thick, prosthetic valve rocking, sinus of Valsalva aneurysm, or perivalvlar density in the septum of $14 \mathrm{~mm}$ or more. When these factors are considered, the positive and negative predictive values are $86 \%$ and $87 \%$ respectively. ${ }^{15}$ Transoesophageal echocardiography is particularly helpful in diagnosing this complication of infective endocarditis ${ }^{16}$ and magnetic resonance imaging may also clearly show an aortic root abscess. ${ }^{17}$ The role of cardiac catheterisation in patients with infective endocarditis is debatable but most would advise its use before cardiac surgery ${ }^{18-20}$ although the rationale for this, resting as it does upon diagnostic accuracy, is being constantly eroded as non-invasive diagnostic techniques improve. Interestingly cardiac catheterisation may be much safer than is often thought. In one study of 35 patients with infective endocarditis undergoing cardiac catheterisation there was not one embolic episode despite vegetations being seen echocardiographically on 15 of the 21 valves crossed by the catheter. ${ }^{20}$ Similar experience has also been reported in another study. ${ }^{21}$ We would not advocate crossing infected valves but think that aortography can be safely used in endocarditis of the aortic valve.

An aortic root abscess itself does not absolutely indicate the necessity for cardiac surgery, ${ }^{13}$ and these abscesses have occasionally healed with medical treatment alone. ${ }^{17}$ Some studies, however, show an improved survival rate with operative intervention in infective endocarditis in general especially when associated with a prosthetic valve. ${ }^{1822}$ If surgery is performed mortality is significantly higher in those with an aortic root abscess (13.6\% compared with $2 \cdot 2 \%$ for those without this complication). ${ }^{13}$

This case suggests that a blood culture growing Propionibacterium acnes should not be dismissed as a contaminant without first considering the clinical circumstances. In this patient Propionibacterium acnes caused an 
aortic root abscess. This supports the current opinion that an aortic root abscess is not necessarily associated with more virulent microorganisms.

1 Wilson APR, Felmingham D, Gruneberg RN, Treasure T, Sturridge MF. Contamination of blood during cardiopulmonary bypass: the effect of antibiotic prophylaxis. $J$ Hosp Infect 1988;12:35-42.

2 Yocum RC, McArthur J, Petty BG, Diehl AM, Moench TR Septic arthritis caused by Propionibacterium acnes. $J A M A$ 1982;248(14):1740-1.

3 Schlesinger JJ, Ross AL. Propionibacterium acnes meningitis in a previously normal adult. Arch Intern Med gitis in a previou.

4 Maibach HI. Scalp pustules due to Corynebacterium acnes. Arch Dermatol 1967;96:453-5.

5 Newman JH, Mitchell RG. Diptheroid infection of the cervical spine. Acta Orthop Scand 1975;46:67-70.

6 Skinner PR, Taylor AJ, Coakham H. Propionibacteria as a cause of shunt and neurosurgical infections. J Clin Patho 085-90.

7 Friedman E, Peyman GA, May DR. Endophthlamitis caused by propionibacterium acnes. Can J Opthalmol 1978;13:50-2.

8 O'Neill TM, Hone R, Blake S. Prosthetic valve endocarditi caused by Propionibacterium acnes. BMJ 1988;296:1444.

9 Lewis JF, Abramson JH. Endocarditis due to Propionibacterium acnes. Am J Clin Pathol 1980;74:690-2.

10 Wilson WR, Martin WJ, Widowske CJ, et al Anaerobic bacteraemia. Mayo Clin Proc 1972;47:639-87.

11 Sheldon WH, Golden A. Abscess of the valve rings of the heart, a frequent but not well recognised complication of acute bacterial endocarditis. Circulation 1951;iv:1-12

12 Utley JR, Mills J. Annular erosion and pericarditiscomplications of endocarditis of the aortic root. J Thorac complications of endocarditis of

13 John RM, Pugsley W, Treasure T, Sturridge MF, Swanton H. Aortic root complications of infective endocarditisinfluence on surgical outcome. Eur Heart J 1991;12:241-8.

14 Arnett EN, Roberts WC. Valve ring abscess in active infective endocarditis. Circulation 1976;54:140-5.

15 Ellis SG, Goldstein J, Popp RL. Detection of endocarditisassociated perivalvular abscess by two dimensional echocardiography. J Am Coll Cardiol 1985;5:647-53.

16 Daniel WG, Schroder E, Mugge A, Lichten PR. Transoesophageal echocardiography in infective endocarditis. $A m J$ Cardiac Imaging 1988;2:78-85.

17 Jeang MK, Fuentes F, Gately A, Byrnes J, Lewis M. Aortic root abscess: initial experience using magnetic resonance imaging. Chest 1986;89:613-5.

18 Lau JM, Guinn GA, Beall AC Jr, et al. Operative techniques in infective endocarditis. Annals Thorac Surg 1981;32. in infectiv.

19 Cheitlin MD, Mills J. Infective endocarditis. Is cardiac catherisation usually needed before cardiac surgery? Chest catherisatio

20 Welton DE, Young JB, Raizner AE, et al. Value and safety of cardiac catheterisation during active infective endocarditis. Am J Cardiol 1979;44:1306-10.

21 Mills J, Abbott J, Utley JR, Ryan C. Role of cardiac catheterisation in infective endocarditis. Chest 1977;72: 576-82.

22 Nihoyannopoulos P, Oakley CM, Exadactlos N, Ribeiro P Westaby S, Foale RA. Duration of symptoms and the effects of a more aggressive surgical policy: two factors affecting prognosis of infective endocarditis. Eur Heart $J$ 1985;6:380-90. 